\title{
Human Ecology as Philosophy
}

\author{
Carleton B. Christensen ${ }^{1}$ \\ School of Philosophy, Research School of Social Sciences \\ College of Arts \& Social Sciences \\ The Australian National University
}

\section{Abstract}

This paper articulates the essentially philosophical character of human ecology. The first section argues that the often-noted concern of human ecology for both sustainability and equity is best understood as a concern to help humans implicated in problematic human-environment interactions to identify how to refashion these interactions so as to enable a more sustainable balance between the moral claims of others and their own needs and desires. Human ecology is therefore governed by a unitary practical interest in facilitating a more sustainable balance between virtue and happiness-living well in Aristotle's sense. If this is so, then human ecology must be done, in certain phases of its practice, as philosophy. The second section then illustrates how this general conception applies to and shapes the investigation of a concrete issue - consumption - particularly in first world economies. It also shows how, given this conception of human ecology as philosophy, this issue is not just one important target of investigation alongside others but the central human ecological topic. Finally, the third section argues that human ecology, done as philosophy, also requires grounding in philosophy. Specifically, it needs a general account of what it is to be the rational animals we humans are since only this can give action-guiding content to the idea of living well without tendentiously prescribing any specific form of life. In conclusion, it is argued that the philosophical character of human ecology explains what it means to describe it as a multi-, inter-, trans-, and even adisciplinary fusion of biological and social sciences.

Keywords: consumption, critical theory, living well, philosophy, rationality, sustainablity

\section{Introduction}

Since its inception as "a fusion of biological and social sciences in the early twentieth century," (Dyball, 2010, p. 273) human ecology has been variously described as (a) multidisciplinary - in that it draws upon the insights of different disciplines - ; (b) interdisciplinary - in that it integrates the insights of other disciplines into a whole greater than the sum of its parts-; and

1 Author contact: carleton.christensen@anu.edu.au. 
(c) transdisciplinary - beyond all disciplines and therefore adisciplinary, hence not really a discipline at all. But what does it mean to characterize human ecology in these successively more radical terms? They are, I believe, inchoate attempts to articulate the following thesis: Human ecology must be done, in certain phases of its practice, as philosophy and indeed is crucially reliant on strictly philosophical reflection. ${ }^{2}$ Only by grounding human ecology as philosophy (as discussed in Section 1) and in philosophy (as discussed in Section 3) can one see what it is to genuinely 'fuse' natural and social scientific disciplines in a coherent unity which explains why it has been successively characterized as multi-, inter-, trans-, and ultimately adisciplinary. Thereby human ecology is strengthened both theoretically and practically: theoretically, in that one has a clearer understanding of what, as a human ecologist, one's task is; and practically, in that one sees how ambitious and politically relevant the task is.

Inevitably, then, much of this paper will work in the language of philosophy, with which many readers of Human Ecology Review will not be familiar. This paper is, however, envisaged as the first in a series in the course of which the philosophical dimensions and presuppositions of human ecology will be further spelled out. This will progressively make the philosophical terminology and style employed here more accessible to readers less familiar with philosophy in general.

\section{The character of human ecology as practically interested}

Let the object domain of a form of inquiry be the class of entities with which this form of inquiry is essentially concerned. An object domain is thus a class of entities in their capacity as constituted in such a way that they can occur in the kinds of relation which a particular form of theoretical inquiry essentially seeks to comprehend. Thus, physics has as its object domain a class of entities which are so constituted as to stand in distinctively physical relations, that is, causal interactions of the kind in which an entity is implicated by virtue of having physical properties. Similarly, the historiography of, say, Germany in the 19th century has as its object domain a class of entities so constituted as to stand in historical relations, specifically those pertaining to German history of the 19th century. Finally, mathematics has as its object domain a class of entities so constituted as to stand in distinctively mathematical relations. ${ }^{3}$

\footnotetext{
2 Of course, in saying this, I mean much more than that human ecology should avail itself of the philosophical tradition.

3 Note that I am deliberately leaving open what physical, German-historical, and mathematical properties are. This is because I want to allow that what one understands by a physical, historical, or mathematical property may evolve.
} 
"Human ecology is about the interrelationships between humans, their cultures and their ecosystems" (Dyball, 2010, p. 273). In other words, it investigates the complex web of causal relations which exist between human beings, their cultural and social practices, and the ecosystems in which these are embedded. We may therefore say that its object domain is the class of human-environment interactions. More precisely, it is the class of entities implicated in these interactions by virtue of having those properties or standing in those relations which shape these interactions. There is, however, a crucial difference between this object domain and those of physics, historiography, and mathematics. The object domain of physics is understood to be unified by natural laws. It is the defining task of physics to find these laws. The object domain of a particular form of historiography, for example, of Germany in the 19th century, is not unified in this sense. Nonetheless, this domain contains items which are intrinsically significant, ${ }^{4}$ that is, significant in the sense that they are understood to have made Germany and Germans what they are today. And understanding how Germany and the Germans have become what they are is something not, or at least not just, practically useful, in that it helps us to deal with Germany and Germans; ${ }^{5}$ it is interesting in its own right. So here, too, something unifies the object domain, making it a worthy object of investigation in its own right: the idea of there being a coherent story to tell about how an important country, culture, and people have emerged as what they are today. ${ }^{6}$ Finally, the object domain of any particular kind of mathematics is understood to be unified by a set of axiomatic principles constitutive of the kind of mathematical entity at issue. It is the task of any given branch of mathematics to uncover the relevant set of principles - that underlying unity definitive of an object domain which is perhaps the example par excellence of something worth knowing for its own sake.

But the object domain of human ecology is not like this. It is not presumed to possess an underlying unity, whether of natural law, narrative significance, or axiomatic principle. Rather, it is understood to be a motley affair whose unity lies in the fact that human-environment interactions have become practically problematic. In other words, the object domain of human ecology is picked out by a practical interest underpinned by concern about human-environment interactions rather than by a theoretical interest affectively underpinned by what Aristotle called wonder (thaumazein). ${ }^{7}$ In this regard, human ecology is

\footnotetext{
4 Obviously, not everything which happened in Germany in the 19th century is of historical interest, hence belongs to the object domain of that form of historical inquiry which is the historiography of Germany in the 19th century.

5 It is in fact arguable whether such historical knowledge is in this way 'useful' at all.

6 It is worth noting that something at least analogous to such narrative unity can be found in disciplines which are not so-called Geisteswissenschaften (humanities). Thus, the object domains of natural history, the evolution of the Earth, etc. are presumed to possess an at least quasi-narrative unity.

7 Wonder is to be distinguished from mere curiosity, however intellectual, because it involves awe, hence recognition of value - beauty, elegance, simplicity, or perhaps, nobility, heroism, creativity, etc. Such recognition of value can be entirely absent from curiosity, for which reason one can speak of a prurient curiosity but not of a prurient wonder.
} 
like engineering or rather the applied science which underpins engineering; for example, research undertaken in order to determine how the reproductive system works so as then to engineer safe and effective means of contraception.

There is, however, also a crucial difference: the object domain of a particular form of applied science is any kind of causal interaction by understanding which one might potentially achieve, through the engineering of appropriate technological solutions, a specific human benefit. So the practical interest at issue here is purely prudential in the sense that it is a concern to know how certain things work for the sake of identifying, or at least enabling the identification of, effective technological means of bringing about certain results beneficial to us. By contrast, the practical interest which leads one to select human-environment interactions as one's domain of theoretical investigation is not simply prudential - as if one were concerned merely to understand these interactions simply in order to devise better ways of protecting and maintaining ecosystems of value to $u s .{ }^{8}$ This interest is also ethical: one is concerned to understand these systems in order to derive just ways of protecting and maintaining ecosystems of value to us. ${ }^{9}$ In one's account of human-environment interactions, one is also concerned to identify their ethical implications and consequences for those morally considerable beings; in particular, for those other human beings implicated in and affected by them.

If, however, the object domain definitive of human ecology is not intrinsically unified in the sense in which those of physics, history, or mathematics are, then human ecology can no more be pursued in purely disinterested, merely theoretical fashion than can engineering or applied science. This does not mean, of course, that an individual human ecologist might not practice the trade out of mere intellectual curiosity. The point here concerns the institution or cognitive practice of human ecology, not individual human ecologists. If the institution or cognitive practice of human ecology were merely an exercise in knowledge for knowledge's sake, then, in contrast to physics, historiography, or mathematics, it would be merely entertaining, a hobby, in the manner of, say, train-spotting. No doubt train-spotting can and perhaps does have its congresses and journals, its experts and keynote speakers. Even so, it remains a diversion. By contrast, physics seeks to know the innermost lawfulness of the physical, and this is something truly wondrous. This innermost lawfulness makes the knowledge gained by physics something worthwhile, something valuable and valued, in a way in which the knowledge gained in train-spotting is not. In this sense, then, physics is serious in a way train-spotting is not. Independently of the

8 Note that the phrase 'of value' allows that the value in question may not be simply prudential but, say, aesthetic.

9 Veronica Bullock has pointed out to me in conversation that the same might well be true of the science of conserving artefacts and other cultural items for exhibition. 
motivations of any individual physicist, physics is a cognitive practice embedded in and sustained by the shared social conviction that what it accomplishes is valuable in and of itself. It is thus a cognitive practice essentially characterized by the normativized collective belief, hence normative expectation, that one does physics because one is intellectually curious about a presumed innermost lawfulness of the physical.

So, too, with human ecology: it is serious in a way train-spotting is not. Independently of the motivations of any individual human ecologist, it is a cognitive practice embedded in and sustained by the normativized collective belief that what it accomplishes is valuable, not in and of itself, but for practical reasons - it permits us to understand phenomena with critical prudential and ethical consequences. It is thus a cognitive practice essentially characterized by the normative expectation that one engages in human ecology because one is concerned about these prudential and ethical consequences. Evidently, if this is so, then as a rule human ecologists will pursue human ecology out of a combined prudential and ethical concern. As a rule, one cannot do human ecology disinterestedly, out of mere intellectual curiosity.

This response to one objection intimates the reply to another. One might grant that human ecology is defined by an essentially practical interest in order then to object that this practical interest might be merely prudential. It is, after all, possible that someone might naively believe that current human-environment interactions do not harm any morally considerable third party but merely threaten the individuals and societies which engage in them. Such a person would then engage in human ecology merely for prudential reasons. But as with the possibility of doing human ecology out of mere curiosity, so, too, with this one: we are discussing the institution or practice of human ecology, not the psychology of the individuals who practice it. Human ecology is a cognitive practice which is essentially structured by the normativized collective expectation that one engage in it out of a concern not just for the prudential but also for the ethical consequences of human-environment interactions. To be what counts as a good, effective human ecologist, one therefore needs as a rule this motivation and when, exceptionally, one does not, one is not doing human ecology properly.

At this point, a crucial question arises: If human ecology is constituted by a practical interest both prudential and ethical in a way in which the practical interest of applied science is not, then how do these two dimensions stand to one another? Surely they do not sit indifferently and contingently alongside one another but rather are intimately bound up with one another. In some way, they must surely form an inseparable unity. But what could this mean? Through interacting with the environment humans seek to satisfy various needs or desires. At the same time, they typically know any such interaction to stand, 
like any human action, under the moral obligation that it not be undertaken in a fashion which disregards the interests of morally considerable beings potentially affected by it. So any human being, simply in virtue of standing, hence knowing him- or herself to stand, under this moral obligation confronts the task of finding some way to mediate between the prudential and the ethical, that is, to find some way in which one can satisfy need and desire while fulfilling the requirements of ethics and vice versa.

Regularly and reliably accomplishing this mediation in the conduct of one's affairs is what Aristotle called living well. ${ }^{10}$ It follows trivially from this characterization of living well that a life lived well - the good life - is neither simply virtuous nor simply happy, but rather both at once. Relatedly, the good person is not simply someone who sacrifices desire to ethics, but rather someone who has an accurate sense of their own entitlement to desire satisfaction. Moreover, living well in this sense, that is, existing as a process of mediating ethics and desire with one another, is objective happiness-objective in the sense that all human beings, unless they are conscienceless psychopaths, would acknowledge it as the optimal way to live, even if they do not regard themselves as having the moral character required for being able to live in this manner. Evidently, living well is not happiness in the sense of feeling good, in particular, about oneself. It is thus not what these days is called well-being. Rather, it is happiness in the sense of contentment and this is a state one can be in even though one is not living in the most comfortable or commodious of conditions and even though one knows one has not achieved all one could have. ${ }^{11}$

This conception of living well has both internal psychological and external social and biophysical implications: as a rule, if not always, human beings must be psychologically disposed to seek this mediation in the conduct of their affairs. Equally, their external situation, which comprises both the social and the natural circumstances under which they live, must be such as to permit them regularly to accomplish this mediation. This yields two further important notions: firstly, one is a good person, that is, of good moral character, insofar as one is psychologically disposed to living well. Secondly, a society is a good one insofar as it enables individuals to develop and realize good moral character. Note that this will involve not only appropriate practices of character formation and the right social relations, it will also require society to have an appropriate relation to its biophysical environment. A good society is one which enables seekers of happiness to be upright, lovers of justice happy, across psychological, social, and natural dimensions.

10 Specifically, it is what he called sôphrosynê — see Aristotle (2011/1941, 1140bl2).

11 It is, for example, quite possible to be happy in this sense - content, at peace with oneself and the world-even in a hospice. 
At this point, we may venture the following speculative thought: In the practical interest constitutive of human ecology the prudential and the ethical are indeed inseparably bound up with one another and they are so because this interest, properly understood, lies not just in listing the various ways in which the human-environment interaction under investigation is prudentially unwise and/or morally wrong, but rather in exploring these ways in their unity as detracting from living well. And the point of thus exploring how the human-environment interaction under investigation undermines living well is to determine how this human-environment interaction could be so rearranged that it enables, for those who engage in it, a better realization of living well.

At first sight, this might seem little more than the anodyne point that human ecology seeks, through the knowledge it provides, to contribute to so-called "win/win" solutions. There is, however, more meat to the idea than this. Firstly, from the substantive perspective of what human ecology accomplishes, it possess a hidden depth of content. It is often hard to determine just how, in the concrete circumstances, one might reorder a human-environment interaction so as to mediate as well as possible in the circumstances between ethics and desire. In particular, what often makes this so hard is that the specific desire at issue is itself dysfunctional, hence is itself what must change; there is no clever way to rearrange things which would permit desire to be satisfied without injustice. This means that human ecology is committed by its constitutive practical interest to exploring a human-environment interaction with a view to determining how the specific desires, hence underlying affective dispositions, ${ }^{12}$ of those engaged in the interaction might be reconfigured to make them more conducive to living well. In other words, since desires and affective dispositions are the springs of purposive behavior and action, human ecology is committed to exploring the possibilities of so-called behavioral change in quite radical fashion, up to and including the study of how, in the concrete circumstances, those involved in problematic interaction might be brought not to desire and not to feel in the manner which drives this interaction. Evidently, this points to the need for an account of what desire and affective disposition essentially are. In particular, it points to the need to investigate first whether human beings have them under their rational control, such that they can reconfigure their patterns of desire and affect in reflective fashion; and then, if this is so, under what conditions and in what way such rational control is effectively exercised. ${ }^{13}$

12 By an affective disposition I mean a capacity to be affected in some way, either viscerally (hunger, pain or pleasure) or emotionally (grief or joy, amused or displeased, etc.). Affective dispositions in this sense make it possible to have desires: I desire to eat because I am hungry, I desire to help a certain person because I love her-or indeed perhaps because I would feel ashamed of myself if I did not help. The capacity for such complex emotions as guilt and self-respect, shame and self-esteem (which pairs are not to be confused with one another!) are extremely important affective dispositions.

13 More will be said below, particularly in Section 3, about the nature of this investigation. 
Secondly, also from the methodological perspective of how human ecology accomplishes what it accomplishes, this idea possesses a hidden depth of content. The constitutive practical interest of human ecology impacts upon how it individuates the human-environment interactions with which it deals. Obviously, if one is investigating a problematic human-environment interaction not simply in order to list its prudentially and ethically negative consequences but also in order to determine how it measures up as enabling those who engage in it to live well, then one cannot be investigating this interaction in isolation. Identifying something which would appropriately recognize the interests of all involved ${ }^{14}$ will clearly require one to see this interaction in both its biophysical and its socioeconomic, political, cultural, and historical context. So from the outset, the human-environment interaction under investigation is picked out as a part belonging to (perhaps larger parts of) a biophysical, socioeconomic, cultural, and historical whole - to an entire form of human life. Furthermore, since human ecology is practically and not merely theoretically interested, this form of life is either directly or indirectly our own. Australian human ecologists could, for example, be investigating Filipino fishing practices, or, in a more historical mode, the land management practices of Australian Aboriginals prior to European colonization. Either way, as human ecologists they are investigating such human-environment interactions because they believe that understanding them is relevant to understanding and better dealing with their own current human-environment interactions, understood as aspects or parts of their own current form of life.

This shows the widely acknowledged holism (Dyball, 2010, p. 1) of human ecology to have a distinctive character which distances it from its origins in ecology as a natural science and permits it to reach out to the social sciences. I have claimed that the practical interest constitutive of human ecology is not simply the sum of two concerns contingently lumped together, on the one hand, a concern to ascertain what prudentially problematic features a given humanenvironment interaction might have, and on the other, a concern to ascertain what its ethically problematic features might be. Rather, I have suggested that these twin concerns are but aspects or dimensions of the one deeper practical interest in ascertaining how concretely the human-environment interaction does or does not facilitate living well. And by an understanding of how concretely a particular kind of engagement with the world does and does not facilitate living well on the part of those thus engaged, I do not mean simply knowledge of certain superficially observable features of the engagement as prudentially or ethically bad. Rather, I mean a grasp of how things actually are in their character as less than they might potentially be. To understand how concretely a particular kind of engagement with the world does and does

14 This is, of course, the really substantive idea behind talk of a "win/win" solution. 
not facilitate living well on the part of those engaged in it is thus to grasp what it is actually in essential relation to an unrealized potential inherent to it. Such understanding is what human ecology must aim at if it is governed by a genuinely practical interest in knowing how a human-environment interaction does or does not facilitate living well - knowing how in a sense which insinuates knowing what to concretely do in response to the impediments to living well the human ecologist discerns.

Since, however, knowledge in this strong sense of how a particular humanenvironment interaction impedes living well does not leap out at the investigator - it is not superficially obvious in the way in which, say, isolated moral blemishes can be-human ecology is defined by a deep and complex task. It seeks not just to list problematic features of the human-environment interaction it is investigating; it also seeks to identify practically available opportunities for developing out of this interaction something which better approximates to living well-better approximates in that it better gives all morally considerable parties their due, hence better balances ethics and desire. Accomplishing this must be a process in which, through ongoing exploration of and negotiation with the context, the investigation lets the human-environment interaction at issue appear in its character as a lesser version of something better. Evidently, a crucial resource in the development of this are the human beings engaged in or affected by the interaction - the stakeholders. Insofar as human ecology is ultimately concerned with understanding how concretely a particular human-environment interaction does and does not facilitate living well, hence must ascertain concretely how things might be better, it must draw upon the knowledge and experience of those engaged in and affected by it. It must make them, to some extent, participants in the investigation.

This immediately gives to human ecology an inherently critical character, in the sense intended by such critical theorists as Theodor Adorno, Max Horkheimer, and Herbert Marcuse. By critical theory, these thinkers meant a theoretical practice which was inherently evaluative: to engage in it was not simply to come up with claims about how things are from which one could only proceed to claims about how they might be better by importing normative and axiological premises from outside. Rather, to engage in it was to come up with claims about members of the object domain which in and of themselves entailed a certain kind of evaluation of these members. To investigate phenomena from the perspective of whether and in what ways they enable or disable living well is, as we have seen, to set oneself the task of exploring them in such a manner that they progressively reveal themselves as aspects of a form of life which would be better in such and such ways. The cognitive goal is to reveal the form of life of which these phenomena are parts not just in its actuality or positivity - what it factually is - but also and primarily in its potentiality or negativity - what 
it is not but could be. Human ecology seeks ultimately to move beyond merely establishing what is problematic in a human-environment interaction in order to glimpse that potential form of life relative to which the actual one appears as less adequate by virtue of containing this human-environment interaction.

An example will make this clearer: Historians can investigate the interaction between a Roman patrician and his Greek tutor in straightforwardly positive fashion, noting, for example, that the latter is a slave whom the former can and often does treat as a mere thing to be used, whom, however, the former does and indeed must treat with deference when learning from him. But precisely for this reason we intuitively recognize that this characterization leaves something unsaid, namely, that there is something cognitively dissonant about the interaction in relation to the patrician's behavior overall: how the patrician behaves when learning shows that the tutor is not a mere thing to be used, hence should not be a slave. Should our historians go on to articulate this, they would obviously be assessing the interaction. And their assessment would be at least ethical: these historians would be applying the general norm that something capable of teaching should never be treated simply as a means but always also as an end in itself. Crucially, they would be assuming that this norm were something acknowledged not just by them themselves but also by the patrician-implicitly acknowledged in the way the latter behaves when being taught. Just this, however, means that the historians' primary assessment would be an ontological one: From the outset, they would have picked the patrician and his behavior out as something to which this norm applies, hence from the outset they are seeing the actual interaction as inherently pointing towards a not-yetrealized one in which those involved have received the due the character of their interaction implies - a counterfactual interaction, therefore, in which the slave would not be a slave. This would be to assess the actual interaction as (part of) an imperfect form of living well, whereby the notion of living well would serve as a standard in the ontological sense that it defines a possibility inherent in the actual interaction of which this interaction is a suboptimal realization.

\section{The study of consumption and the critique of consumerism}

I want now to illustrate how the general conception just sketched applies to and shapes the investigation of a concrete issue. I have chosen this issue because, as we shall see towards the end of this section, when human ecology is conceived as inherently philosophical in the manner described in Section 1, this issue shows itself to be not so much just one important target of investigation alongside others but, in a sense to be explained, the central human ecological topic. 
It is widely acknowledged that problems of sustainability have much to do with the character, quantity, and rate of consumption, particularly in first world economies. In the literature on consumption and consumerism there are two broad traditions, each strong where the other is weak. On the one hand, there is a tradition that starts from the assumption that consumption is a process through which individuals not merely satisfy needs and desires, but also signal to others such things as status, power, identity, and/or individuality. Acknowledgment by others of the status, power, identity, or individuality thereby signaled is then construed as confirming individuals in their own sense of self, hence as a source of their self-esteem. Often, the signaling role of consumption is seen as manipulable through advertising by vested interests. When it is thus manipulated, consumption becomes consumerism, with consequences bad for consumers themselves: loss of autonomy, 'inauthentic' selfhood, and the absence of 'true' happiness. Evidently, this tradition, which reaches from Thorstein Veblen (1994/1899) through J. K. Galbraith (1958), Vance Packard (1957), and Erich Fromm (1976) to Juliet Schor (1998) and Clive Hamilton and Richard Denniss (2005), seeks not just an account of consumption but a critique of consumerism.

On the other hand, there is a tradition which proceeds ethnographically, examining diverse practices of consumption in order to determine what exactly individual consumers do when they use consumer goods and services, hence why they purchase them. This tradition ascertains that consumers frequently use consumer goods and services in such spontaneous and creative ways that no advertiser could anticipate this use. To this extent, and in contrast to what many in the first tradition maintain, the desires driving consumption cannot be literally manufactured by producers through marketing. Furthermore, no obvious sense emerges in which consumption in late modern capitalist societies is bad for consumers themselves, hence consumerist. The second tradition thus provides no basis for the kind of critique characteristic of the first. Indeed, sometimes this second tradition construes ostensibly consumerist consumption positively, as providing opportunities for creative self-expression and fantasysee Bauman $(2000,2001)$ and Campbell (1987). Other representatives of the second, noncritical tradition include Daniel Miller (2001), Sophie Woodward (Miller \& Woodward 2012), Richard Wilk (2001), and, in a different way, Elizabeth Shove (2003; and Shove et al. 2009).

The second tradition stands on empirically stronger ground: most forms of consumption and consumer do not correspond to the picture painted of them by the first tradition. In fact, the first tradition illicitly takes a particular form of consumption-conspicuous consumption-as representative of all consumption. Furthermore, it paints a distorted picture of conspicuous consumption. In particular, it construes the conspicuous consumer as a slave 
of advertising whose desire for a product is just as much manufactured by the producer through advertising as the product itself. This "productivist" picture of consumption grossly misrepresents how advertising actually works. Yet there is a certain legitimacy to the concern of many within the first tradition to identify a sense in which contemporary consumption is consumerist, that is, bad not just for certain third parties but for consumers themselves. If it can be shown that such consumption is not truly in the interest of those who engage in it, then one will have uncovered a powerful motivation for behavioral change. This is evidently an attractive feature for those seeking more sustainable kinds, quantities, and speeds of consumption. One would like, therefore, to preserve this critical dimension of (much of) the first tradition even as one preserves the empirical accuracy of the second. A synthesis of the two traditions is needed.

Recall now the account implicit in Aristotle of the formal structure of living well: To live well is to reliably and regularly, if not necessarily always, mediate successfully between ethics and desire, such that as a rule the demands of the one are reconciled with the demands of the other. Clearly, being able to live well in this sense is a function both of one's internal desires and general moral character and of one's external social and natural circumstances. This provides a clue as to how one might interpret practices of consumption in late modern consumer capitalist society as "consumerist," that is, bad for consumers themselves even though such consumers might very well enjoy the fruits of consumer society and even though they are so little manipulated by advertisers that they display a relative autonomy in relation to the blandishments of marketing. For one can imagine a situation in which the totality of consumption practices becomes dysfunctional in the sense that although this totality might provide a vast choice of high-quality, low-cost opportunities for consumption, the practices of production and distribution needed to sustain this totality involve such speed, change, labor intensity, temporal fragmentation, and social isolation that the capacity for living well is impaired. One needs, for example, to go somewhere and would prefer to use public transport, perhaps because it is environmentally friendlier, hence ethically better, and moreover gives one the chance to read, hence is prudentially better. Unfortunately, one has so much to do, and the public transport system is so inconvenient that one has no choice but to make the short-term rational but long-term irrational decision of traveling by car. Evidently, if such suboptimality is a feature of practical decision-making across many different contexts and individuals, then the capacity of individuals collectively to steer the totality of consumption and production practices will be undermined. The political life of this totality can then only be maintained as a comforting illusion.

There thus lies in this situation of dissonance a possible collective motive for the reorganization of the spheres of consumption and production: less choice of 
low-cost, high-quality goods and services in favor of more time for the kind of reflectiveness, the social and political engagement, and indeed the overall inner composure $^{15}$ which fully rational decision-making, hence living well, requires. Those interested in less choice of low-cost, high-quality goods and services for environmental reasons can therefore exploit this collective dissonance in an argument to the effect that in reality, however advantageous and pleasurable current practices of consumption may be in the short term, in the longer term the kind of lifestyle, and in particular workstyle, they embody is not really worthwhile because it tends to rob us of crucial dimensions of living well: reflectiveness, social and political engagement, and inner composure. Much contemporary consumption is indeed consumerist in the sense desired and the demonstration that it is so is a powerful argument for social change. The harder we have to work in order to maintain such consumption the more powerful this argument will become.

Two important points follow from this sketch of how to provide an account of consumption that is critical without empirical distortion. Firstly, it requires one to investigate consumption in its relation to production, that is, to practices of work. It discloses the dimension of work as something one needs to investigate in order to understand the quality of life in consumer capitalist society and in so doing it reveals this dimension as a possible source of motives for social change, in particular, change towards a less consumerist, hence more sustainable, organization of work and play. All sorts of notions now become targets of critical scrutiny, in particular those associated with the kind of work increasingly demanded by the consumer society, for example, productivity or efficiency, performance, excellence, flexibility, and similar notions. These can now be investigated for the potentially dehumanizing consequences which take the gloss off the bounty of consumer goods and services.

Secondly, the appeal to the notion of living well as the key to a genuinely critical but empirically accurate account of consumer capitalist consumption insinuates the centrality of the issue of consumption for human ecology. Human ecology is an investigation of human-environment interactions motivated by a concern to determine how these can be reorganized along lines that secure sustainability while facilitating living well. But all human-environment interactions are ultimately undertaken because they serve some kind of (end-)consumption, whether the particular interaction at issue be food supply or rest and recreation. So by its very nature human ecology considers human-environment interactions as a unity of production and consumption-more precisely, as a sequence

15 In Meister Eckhart's sense of the term - what he calls Gelassenheit, which has connotations not just of self-composure but of self-surrender, that is, the capacity to put on hold one's own preoccupation and concern with oneself in order to be able to see how things really are, hence what really matters. Self-surrender in this sense is clearly an essential feature of fully rational decision-making. 
of acts of production enabling acts of (end-)consumption. Practices of (end-) consumption are therefore not just contingently a matter for human ecological empirical investigation. ${ }^{16}$

\section{Philosophical foundations in an ontology of self}

The claim that human ecology seeks knowledge useful for transforming human-environment interactions in the direction of sustainable living well would be little more than a slogan had one no principled, theoretical means for determining what it meant, in the specific circumstances under investigation, for rational animals such as we are to live well. One would be forced to rely on pre-philosophical intuitions about what concretely realized, from case to case, the formal structure of living well and such reliance would run the risk of tendentiously favoring certain concrete forms of life and culture over others. Thus, precisely in order to make the notion of living well concrete enough to guide action yet not so concrete as to become a tendentious imposition, human ecology requires a certain kind of philosophical grounding. Specifically, it needs an account of rational animality itself, an account which would identify certain concrete features of which it argued that all forms of living well must exhibit them. Appeal to such features could then guide practical political engagement without fear of tendentiousness.

Now under the plausible assumption that self-conscious subjectivity and rationality requires animality - that is, embodiment in the sense of a capacity both for bodily action and for affective response (feeling, sentiment, emotion, hence vulnerability) - a philosophical account of rational animality would be nothing less than a strictly philosophical ontology of the self, its subjectivity, and its rationality. ${ }^{17}$ The goal of this ontology would be twofold. Firstly, it would seek to elaborate and justify the claim implicit in Section 2 that reflectiveness, social and political engagement, and inner composure are the conditions under which the defining capacity of creatures capable of living well, namely reason, ${ }^{18}$ is optimally exercised, hence are essential features of living well. Evidently, these features prescribe no concrete form of life. Yet they are not so abstract as to permit no inference to operationalizable guidelines for the development of

16 Nor is it surprising that human ecologists, when they seek to identify what current human-environment interactions lack, should so readily turn to notions of enoughness (Genügsamkeit), sufficiency and the like.

17 Demonstrating this assumption would indeed be a principal task for such an ontology of self.

18 It follows trivially from the characterization of the formal structure of living well given here that one can only live well if one is capable of ethical judgement and deliberation. For this reason, as Aristotle points out, only rational animals can live well. Of course, as he also points out, animals not capable of self-consciousness and rationality, for example, oxen, can lead pleasurable, pain-free lives. But they cannot be happy in Aristotle's sophisticated sense. 
political programs and policies. Thus, secondly, on the basis of its neither too abstract nor too concrete understanding of living well, the envisaged ontology of self, subjectivity, and rationality would seek to justify both the avoidance of complexity and tight coupling, and the need for the slow and for a nonhubristic precautionary stance towards social and environmental intervention. For these it would show to be the collective "mindset" required for creating and maintaining the social relations and psychological dispositions which encourage reflectiveness, social and political engagement, and inner composure.

Implicit in these two interrelated goals is an important specific task required of the envisaged ontology. In Section 1 it was pointed out how, on the conception of it sketched there, human ecology was committed to exploring the possibilities of potentially quite radical behavioral change, up to and including the identification of how those involved in problematic interaction might be brought not to desire and not to feel in the manner driving this interaction. Now everyday, pre-theoretical experience already testifies that the desires and affectivities of distinctively self-conscious, at least moderately rational subjects are not brute, unchangeable facts of animal constitution, such that nothing can ever change them. Equally, however, it suggests that such desires and affectivities are not simply artifacts of external, hence purely externally manipulable conditions, for example, the socioeconomic, technologically mediated practices of consumption in which one participates. ${ }^{19}$ In some sense, then, changing them in a more sustainable direction requires intervening to change the internal psychological constitution of the subject itself. But what kind of intervention? Some kind of engineering intervention, such as brainwashing or the administration of drugs? Quite apart from its dubious morality, any such psychoengineering is unlikely to be effective.

For this reason, it was also claimed in Section 1 that human ecology presupposes human beings to have, at least to some sufficient degree, their desires and affectivities under their rational control, such that they can themselves rationally reconfigure their patterns of desire and affect. Human ecology therefore presupposes an account of how this can be so. The envisaged ontology of self and subjectivity must include an ontology of desire and affect which shows first that, as distinctively self-conscious subjects, human beings do have such rational control; and second, in a manner in which our everyday, pre-theoretical experience cannot show, under what conditions and in what ways human beings can exercise this rational control. This ontology would thus describe the nature and extent of the capacity to rationally reconfigure patterns of desire and affective response in the light of the knowledge human ecology provides as to the unsustainability of, for example, current practices of consumption and the hints it gives as to more sustainable alternatives which, 
once habituated to them, we would find to be forms of living at least as well, if not better. What mechanisms of social and psychological compensation must be in place in order for the transition to new, more sustainable forms of desire and affectivity to be so tolerable - which is not to say painless - that one can reliably expect individuals to embark upon it? Evidently, the ontology envisaged here constitutes the distinctively philosophical component of and contribution to a theory of behavioral change. Such a theory would clearly be of importance to the practicing human ecologist since, as already pointed out, patterns of desire and affect play a crucial causal role in currently unsustainable humanenvironment interactions. Human ecology must therefore seek to understand these patterns as well, and to do so with a view to suggesting how they, too, might be changed for the better.

Finally, implicit in the conception of human ecology sketched here lies a decisive metatask for this strictly philosophical account of self and subjectivity. Everything said thus far entails that human ecology understands not just itself but also the humans it investigates as governed by a distinctive practical interest in living well. More precisely, it entails that human beings are, in their capacity as rational animals, essentially oriented towards living well: This is what it is for us to be most fully or optimally as the rational animals we are. The essential character of this orientation explains why all normal, nonpsychopathic human beings would acknowledge living well as the optimal way to live for rational animals even though they themselves may believe they do not have the moral character to do so. It also explains the truth of the claim that most people are not affectively indifferent to right and wrong: most could not be psychopaths but would prefer to do the right thing and will do so provided the costs are not too high. In other words, most people will not ruthlessly seek their own advantage at all cost but will sooner make some sacrifice, however small, in order to do the right thing. Claims such as these create space for something desperately needed in these times of growing eco-despair and -resignation: ${ }^{20}$ faith in the capacity of human beings to deal effectively with such enormous crises as the environmental one. Given this, it becomes imperative to ground, as an essential structure of self and subjectivity, that orientation towards living well which entails the truth of these claims.

\footnotetext{
20 For an example of a powerful manifestation of this, see http://dark-mountain.net/about/manifesto/. Admittedly, just how despairing the Dark Mountain Project really is remains unclear - this because it remains chronically unclear about just what it is rejecting: environmental or ecopolitics, no matter how radical, or merely the light-green panglossian and technocratic politics of government and business.
} 


\section{Conclusion}

Claims that human ecology is multi-, inter-, trans-, and even adisciplinary are not just unclear, they are disconcerting. For if human ecology is all these things, and in particular the latter two, then how can it be anything coherent at all? Is it not rather, as its opponents in academia might allege, a mere hotchpotch of investigations into human-environment interactions which try to be both natural and social science without succeeding at either? Evidently, these worries and allegations presuppose that the notion of discipline has a fairly specific sense. In particular, the notion cannot be understood so broadly that any cognitive practice will count as a discipline since human ecology is obviously a cognitive practice, with its own conventions, congresses, journals, professional networks, and the like. What, then, is a discipline? Surely it is a cognitive practice with an inherently recursive character: a discipline possesses a stable body of agreed-upon results from which current practitioners can and must proceed as an accepted basis for further research, whereby they generate further agreed-upon results from which subsequent practitioners can and must proceed, who in turn generate further agreed-upon results ... and so on, ad indefinitum.

No doubt all cognitive practices conventionally regarded as disciplines only approximate to this ideal. And no doubt some practices approach it better than others. Certainly, different types of discipline approach it in very different ways - for example, English literature as opposed to molecular biology. Human ecology, however, has surely not approached it very much at all. But if human ecology is inherently philosophical, both in the sense that in some phases of its activity it is philosophy and in the sense that it is directly reliant on a strictly philosophical account of self and subjectivity, then one should neither be surprised nor disturbed by this fact. For philosophy only is what it is, and does what it does, by resisting normalization as a recursively structured discipline. This obviously does not mean that it is not a genuinely cognitive practice with a crucial role to play in human culture and advancement. In fact, precisely in its non-normalisability, philosophy is that essential complement to disciplinarity without which the totality of cognitive practice would not be able to radically recast itself - precisely into new disciplines very different from existing ones. Seen in this light, human ecology becomes the distinctively philosophical appropriation of the results of whatever disciplines, techniques, and indeed pre-theoretical, everyday knowledge are needed for providing human society not just with the knowledge but also with the conceptual flexibility it needs in order to generate a creative practical response to the most serious crises human beings have ever confronted. 
The task then becomes that of applying this conception of human ecology as philosophy to specific issues - centrally, of course, to the critical study of consumption but also to many other issues. One such further issue would be the critical study of production, that is, work and its potentially alienated forms in late modern capitalist society. Another would be the conceptual analysis of key concepts used in characterizing human-environment interactions, for example, the urban, the rural, the natural, and the wild, which could be deepened to include reflection on such fundamental ontological categories as those of biophysical limit, system, and causation. Of highly topical political relevance would be the analysis of the legitimacy and limits of growing social tendencies to eco-resignation, as illustrated by the Dark Mountain Project. ${ }^{21}$ Last but not least, there is the critical investigation of mainstream understandings of what problems of sustainability are and how to solve them-more bluntly put, of technocratic thinking. These all represent new and exciting issues for members of the human ecology community to work on into the future.

\section{References}

Aristotle. (2011/1941). Nichomachean ethics. In R. McKeon (Ed.), The basic works of Aristotle (Reprint edition) (pp. 935-1126). New York: Random House.

Bauman, Z. (2000). Liquid modernity. Cambridge: Polity Press.

Bauman, Z. (2001). Consuming life. Journal of Consumer Culture, 1(1), 9-29.

Campbell, C. (1987). The romantic ethic and the spirit of modern consumerism. Oxford: Basil Blackwell.

Dyball, R. (2010). Human ecology as open transdisciplinary inquiry. In V. Brown, J. Harris, \& J. Russell (Eds.), Tackling wicked problems: Through the transdisciplinary imagination (pp. 273-284). London: Earthscan.

Fromm, E. (1976). To have or to be? New York: Harper \& Row.

Galbraith, J. K. (1958). The affluent society. Boston: Houghton-Mifflin.

Hamilton, C., \& Denniss, R. (2005). Affluenza: When too much is never enough. Sydney: Allen \& Unwin.

Miller, D. (2001). The poverty of morality. Journal of Consumer Culture, 1(2), 225-243.

Miller, D., \& Woodward, S. (2012). Blue jeans - The art of the ordinary. Berkeley, CA: University of California Press.

Packard, V. (1957). The hidden persuaders. New York: David McKay. Schor, J. (1998). The overspent American. New York: Harper Collins.

21 See footnote 20 
Shove, E. (2003). Comfort, cleanliness and convenience: The social organization of normality. Oxford: Berg.

Shove, E., Trentmann, F., \& Wilk, R. (2009). Time, consumption and everyday life: practice, materiality and culture. Oxford: Berg Publishers.

Veblen, T. (1994/1899). The theory of the leisure class. New York: Penguin Books.

Wilk, R. (2001). Consuming culture. Journal of Consumer Culture, 1(2), 245-260. 
This text taken from Human Ecology Review Volume 20, Number 2, 2014, published 2014 by ANU Press, The Australian National University, Canberra, Australia. 